\title{
The impact of laser surface treatment on the microstructure, wear resistance and hardness of the AIMg5 aluminum alloy
}

\author{
Wojciech Pakieła ${ }^{1}\left[\right.$ D $\cdot$ Tomasz Tanski $^{1} \cdot$ Zbigniew Brytan $^{1} \cdot$ Grzegorz Chladek $^{1} \cdot$ Katarzyna Pakieła $^{1}$
}

Received: 10 October 2019 / Accepted: 28 January 2020 / Published online: 26 February 2020

(c) The Author(s) 2020

\begin{abstract}
Light metal alloys due to several unique properties such as low density and high corrosion resistance are increasingly used in various technical applications, where the automotive industry is one of the most important sectors. The automotive applications use mostly aluminum alloys, where the strength to density ratio of the material plays a crucial factor. Unfortunately, relatively low mechanical properties limit their applications for parts where a high surface hardness and wear resistance is expected. The classic heat treatment of aluminum alloys can only in some limited ranges improve the bulk material properties. Despite this, surface treatment with laser processing has developed significantly over the past 20 years. The laser beam treatment allows the introduction of a wide range of alloying elements to the surface layer of an aluminum alloy and thus, as a result of the precipitation of numerous intermetallic phases, significantly increases hardness, and abrasion resistance. The purpose of this work was to modify the aluminum surface layer using high-power fiber laser (HPFL). During this process, a mixture of titanium and iron powders $(90 / 10 \mathrm{wt} . \%)$ was introduced onto the surface of the AlMg5 alloy. The microhardness tests carried out by the Vickers method and tribological tests showed a significant increase in mechanical properties in the entire volume of the obtained layer. Research on light and scanning microscopy revealed fragmentation of primary precipitates and the formation of numerous intermetallic phases rich in titanium and aluminum.
\end{abstract}

Keywords Laser treatment $\cdot$ Tribological properties $\cdot$ Aluminium alloy $\cdot$ High power fibre laser $\cdot$ EDS analysis

\section{Introduction}

The dynamic development of the automotive industry forces the use of light metal alloys in new generation vehicles. Aluminum alloys are more often used in modern constructions. This is due to their low density, high corrosion resistance, and good electrical and thermal conductivity $[1,2]$. Unfortunately, due to relatively poor wear resistance, their use is unjustified in some engineering applications [3]. Currently, there are many different methods to improve the strength properties of aluminum alloys. Snopinski et al. improved

Wojciech Pakieła

wojciech.pakiela@polsl.pl

Tomasz Tanski

tomasz.tanski@polsl.pl

1 Division of Materials Processing Technology, Management and Computer Techniques in Materials Science, Institute of Engineering Materials and Biomaterials, Silesian University of Technology, Konarskiego Str 18A, 44-100 Gliwice, Poland the $\mathrm{Al}-\mathrm{Mg}$ alloys mechanical properties through the equal channel angular pressing (ECAP). This type of strengthening significantly improves the strength properties in the entire material volume $[4,5]$. There are also known attempts to improve the tribological properties of $\mathrm{Al}$ alloys using the PVD method [6]. In addition to the above methods, classical heat treatment [7] (saturation and ageing), plastic deformation [8] and HVOF [9, 10] are also often used.

At the turn of the last few years, one can observe a very dynamic development of laser surface treatment methods[11, 12]. There are many reports revealing the widespread use of the laser to improve the mechanical and corrosion properties of various engineering materials [13-15]. Numerous reports reveal the formation of intermetallic phases in the remelting area during laser processing, including light metal alloys. The creation of intermetallic phases allows a significant increase in the hardness and abrasion of aluminum alloys, without a significant increase in mass and interference in the properties of the base material [16-18].

Ti and Al-based intermetallic phases are characterized by, among others, low density, good high temperature strength 
and creep resistance, fatigue, oxidation, and corrosion resistance[19] The introduction of intermetallic phases such as $\mathrm{Al}_{3} \mathrm{Ti}$ or $\mathrm{Al}_{2} \mathrm{Ti}$ allows a significant increase in the strength and hardness of aluminum alloys. As the research shows the density of $\mathrm{Al}_{2} \mathrm{Ti}$ is about $3.53-3.54 \mathrm{~g} / \mathrm{cm}^{3}$, which is less than in the case of $\mathrm{Ti}_{3} \mathrm{Al}$ and compressive yield strength is about $700 \mathrm{MPa}$ at room temperature $[20,21]$. Hsu et al. showed that the introduction of the $\mathrm{Al}_{3} \mathrm{Ti}$ phase into aluminum by friction stir processing allows to obtain a composites layer with increased Young's modulus and strength [22]. The intermetallic phases formed from the combination of $\mathrm{Al}$ and $\mathrm{Fe}$ also increase the strength properties of the layers formed. The hardness of such precipitates, for example $\mathrm{AlFe}_{3}$ may exceed $640 \mathrm{HV}$ [23].

The formation of Al-Ti phases in the remelting area was demonstrated by Chen et al. [24]. The authors demonstrated the formation of, among others, $\mathrm{Al}_{3}$ Ti phases in the welding area when welding sheets made of aluminum (5A06) and titanium alloy (Ti-6Al-4V). Chen received similar results using a laser beam for welding [25]. Majumdar et al. using a laser received layers $\mathrm{Ti} / \mathrm{Al}$ and $\mathrm{Ti} / \mathrm{Al} / \mathrm{Si}$ on the surface of pure titanium [26]. They were characterized by a significant increase in abrasion resistance and a reduction in the friction coefficient of $\mathrm{Ti} / \mathrm{Al}$ layers in relation to the pure titanium. Garcia et al. to increase abrasion resistance, introduced Al-Ti and Al-Ti-N powder into the surface of pure titanium using a $\mathrm{CO}_{2}$ laser [19]. However, there are no reports of surface modification of $\mathrm{Al}-\mathrm{Mg}$ alloys using titanium and iron powders, especially using the high-power fiber laser (HPFL). surfaces and liquid metal from oxidation. A mixture of titanium powder (spheroidal shape) and iron (globular shape) in a proportion of $90 / 10$ by weight was introduced directly into the liquid metal pool using a pressure feeder. During LSA process, a coaxial head was used to evenly feed the alloying powder. The average titanium powder size was $37 \mu \mathrm{m}$ and iron $42 \mu \mathrm{m}$. The LSA parameters are shown in Table 1.

The laser beam was focused on the treated surface using a Reis-Modular Welding Optics AP44 with a focal length of $200 \mathrm{~mm}$. Three laser movements were made to obtain a wide layer. Due to the small sample volume $(20 \times 10 \times 50 \mathrm{~mm})$ between the individual paths a gap of $180 \mathrm{~s}$ was used. The length of each alloying patch was $40 \mathrm{~mm}$. During subsequent paths, a fixed offset of $3 \mathrm{~mm}$ in the $\mathrm{Y}$ axis was used. Keeping $50 \%$ of the overlap on the previous track resulted in a relatively uniform and even bottom of the layer.

Metallographic observations were carried out using a light microscope on polished and etched samples. The LSA surface were electrolytically etched during $120 \mathrm{~s}, 20 \mathrm{~V}$ voltage in $\mathrm{HBF}_{4}$ solution. In addition, polished (neoprene rubber + colloidal suspension of silicon oxide $0.004 \mu \mathrm{m}$ ) but not etched samples were observed. The chemical composition analyses were performed on a scanning electron microscopy (SEM-Supra 35 Zeiss), using X-ray analysis (EDX).

$\mathrm{X}$-ray diffraction was used to identify the intermetallic phases formed in the volume of the LSA layer. Analysis was performed on the PANalytical X'Pert diffractometer, using filtered cobalt anode radiation $(\lambda K \alpha=1.79 \AA)$. The measurements were made with use of a semiconductor detector

\section{Material and experimental procedure}

Aluminum alloy with 5\% magnesium EN AC-AlMg5 was used as the base material (Fig. 1a). During the laser surface alloying process (LSA), a YLS 4000 IPG fiber laser was used with a maximum power of $4 \mathrm{~kW}$ and a wavelength of $1070 \mathrm{~nm}$. Shielding gas (helium) was used to protect the

Table 1 Parameters of laser surface treatment

\begin{tabular}{ll}
\hline Power, $\mathrm{kW}$ & 2.5 \\
\hline Laser spot, $\mathrm{mm}$ & 3 \\
Spot speed, $\mathrm{m} / \mathrm{min}$ & 0.2 \\
Shielding gas & $\mathrm{He}, 2.5 \mathrm{l} / \mathrm{min}$ \\
Powder feed rate & $0.5 \pm 0.05 \mathrm{~g} / \mathrm{min}$ \\
\hline
\end{tabular}

(a)

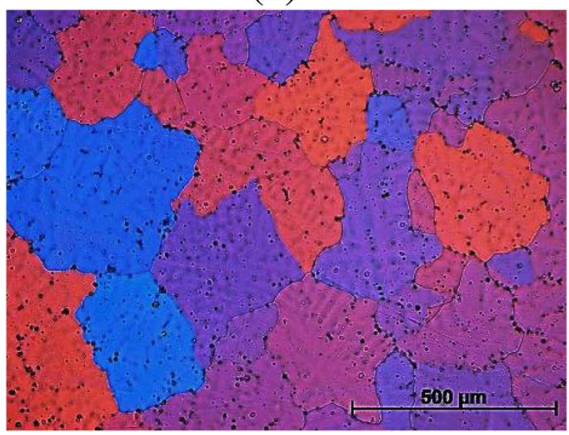

(b)

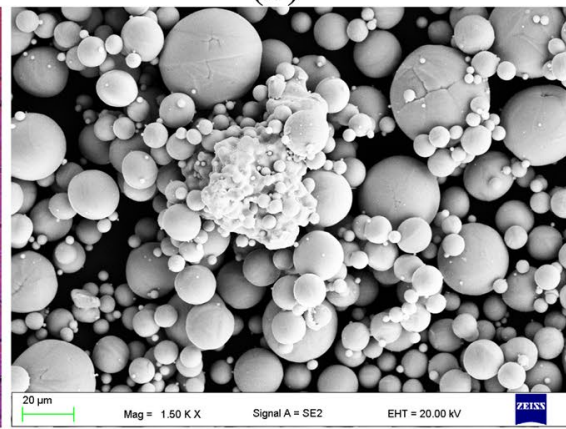

(c)

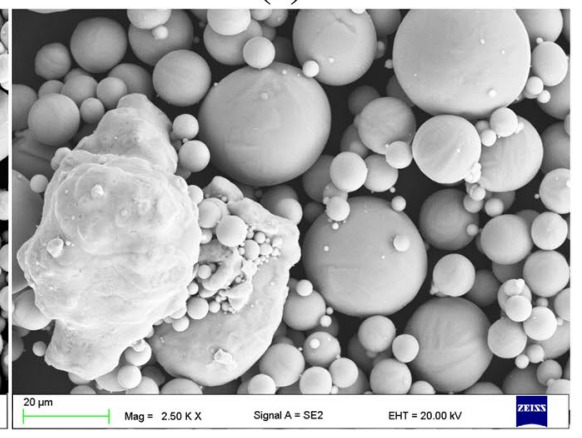

Fig. 1 Microstructure of untreated surface AlMg5-(a) mixture of powders (Ti/Fe) used during LSA—(b, c) 
strip "PIXcell 3D" in two-dimensional area mode at range of $10-120^{\circ}[2 \theta]$ (step $=0.026^{\circ}$, counting time at step $=36.46 \mathrm{~s}$; generator settings: $30 \mathrm{~mA}, 40 \mathrm{kV}$ ).

The layer's hardness was measured using a Rockwell durometer in HRF scale (penetrator-1/16-inch sphere, $60 \mathrm{~kg}$ load). The measurements were made after surface grinding - removing the wavy part of the layer-using abrasive paper with a grain size of $65 \mu \mathrm{m}$. To determine the hardness distribution on the layer cross-section, the Vickers hardness tester $(300 \mathrm{gf} / 15 \mathrm{~s})$ was used. A hardness distribution map of $4.0 \times 6.0 \mathrm{~mm}$ (measuring step " $x$ " and " $y$ ": $0.2 \mathrm{~mm}$ ) was made covering the entire laser-treated area: alloyed layer, heat affected zone and parent material.

The wear resistance of the base material and LSA layers was tested using the ball-on-disk test (the sample rotates around its own axis while the counter-sample is pressed with constant force). A zirconia ceramic ball $6 \mathrm{~mm}$ in diameter was used as a counter-sample. Immediately before the test, the surface was sanded with 65,15 and $5 \mu \mathrm{m}$ abrasive paper. The sample surface and counter-sample surface were then chemically cleaned with methyl alcohol and dried with compressed air. The test parameters are shown in Table 2.

\section{Results}

Application of laser surface treatment (LSA) allows to obtain a very wide range of alloyed layers on almost any metallic material $[13,14,17,18]$. A certain limitation of LSA, as in the case of the cladding process, is the inability to obtain a

Table 2 The ball-on-disk wear test parameters

\begin{tabular}{lllll}
\hline Load, $N$ & $\begin{array}{l}\text { Linear speed, } \\
\mathrm{cm} / \mathrm{s}\end{array}$ & Distance, $\mathrm{m}$ & $\begin{array}{l}\text { Wear track } \\
\text { radius, } \mathrm{mm}\end{array}$ & $\begin{array}{l}\text { Counter } \\
\text { sample }\end{array}$ \\
\hline 10 & 10 & 50 & 2.5 & $\mathrm{Ball-ZrO}_{2}$ \\
\hline
\end{tabular}

perfectly smooth and even surface layer [27, 28]. To ensure adequate surface roughness and waviness, material removal processes such as grinding are necessary. The use of this procedure allows you to remove high waviness especially on the surface of the melting line and high surface roughness, as well as undissolved alloy powder particles present on the surface of LSA. In the present study, the average roughness of the LSA layer before grinding was $6.42 \pm 1.14 \mu \mathrm{m}$. The average width of the alloyed track ( 1 and 2 ) was about $2862 \mu \mathrm{m}$, while the third line was $3200 \mu \mathrm{m}$. The topography of alloyed surface layer as well as its waviness and roughness are shown in Fig. 2. Hardness (HRF) and abrasion resistance measurements were made on a previously ground surface. The surface of both: LSA layers and reference samples (aluminum alloy without LSA) was prepared in the same way.

Metallographic observations using light optical microscopy (LOM) were performed using differential interference contrast (DIC) and polarization. The average grain size in the remelting area ranges from 4 to $42 \mu \mathrm{m}$. The smallest grain size $(4-15 \mu \mathrm{m})$ was observed in the lower part of alloyed area (Fig. 3b), while in the middle and upper part of the remelting zone it was from 25 to $42 \mu \mathrm{m}$ (Fig. 3c). The average grain size of AlMg5 alloy without laser surface treatment was in the range from 300 to $590 \mu \mathrm{m}$ (Fig. 1a, $3 \mathrm{a}$ - "a" lower part of the figure).

Based on the LOM observations, three zones were revealed: a remelting area enriched with alloying elements, the heat affected zone (HAZ) and the parent material. The average depth of alloyed layer was from 1440 to $2168 \mu \mathrm{m}$, while the width of the heat affected zone ranged from 5 to $15 \mu \mathrm{m}$. Due to the large overlap during laser processing (50\%), the depth of alloyed zone was not uniform across its width. The most significant change in layer depth was revealed up to $5 \mathrm{~mm}$ from the beginning of remelting area. After stabilization, the depth differences were about $35 \mu \mathrm{m}$, and the undulations of the lower layer were still visible. In addition, about $550 \mu \mathrm{m}$ of the surface layer thickness was (a)

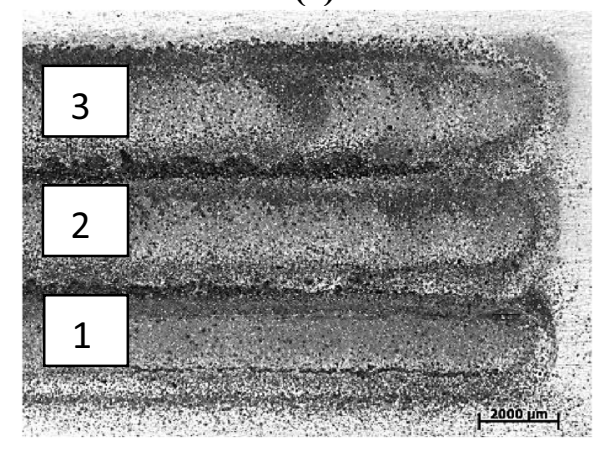

(b)

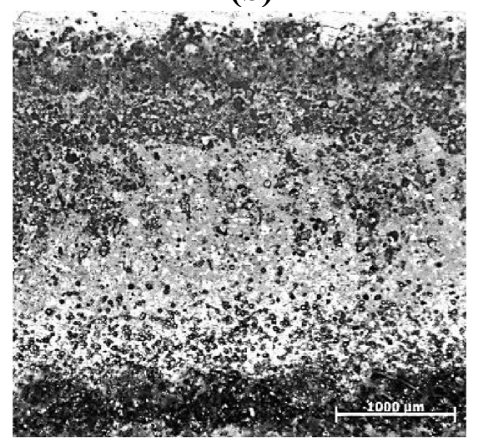

(c)

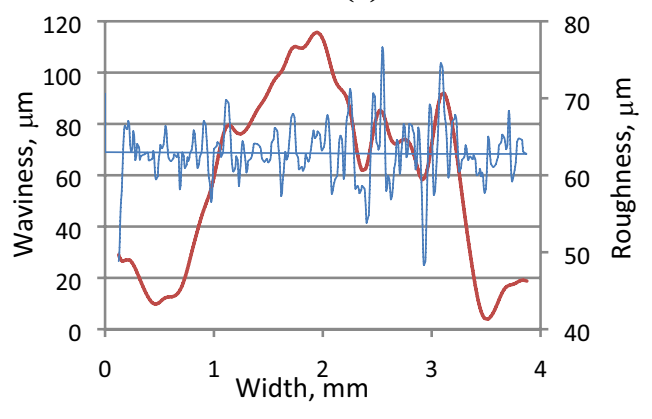

Fig. 2 Topography of the surface layer: a topography of the LSA layer, b surface topography of a single alloyed line no 3 , and $\mathbf{c}$ a surface profile of waviness and roughness of LSA layer 
(a)

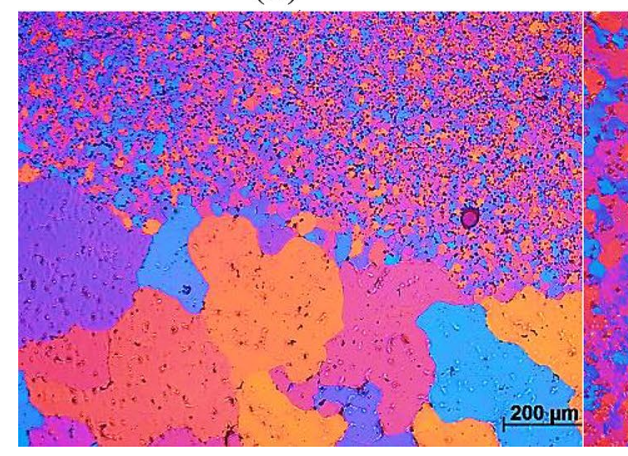

(b)

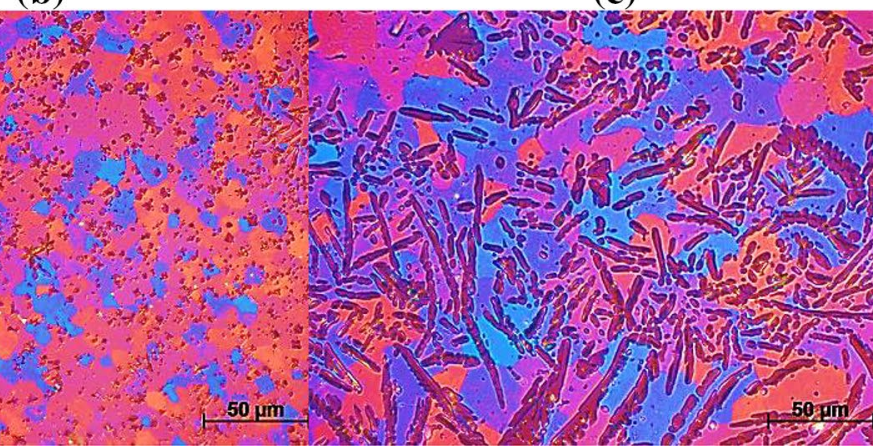

Fig. 3 The microstructure of the alloyed layer: a the lower part of the alloyed layer, with visible coarse grains of the parent material, $\mathbf{b}$ the middle part, $\mathbf{c}$ the upper part

removed at the grinding stage (for tribological and hardness test). As the alloyed layer depth increased, a smaller proportion of the formed phases was observed. The phases formed in the lower part of alloyed layer were of smaller size (Fig. 3b). Spherical dark areas visible in Fig. 3a are insoluble titanium powder particles whose chemical composition was confirmed by EDS analysis.

Based on XRD analysis, the presence of such intermetallic phases as $\mathrm{Al}_{2} \mathrm{Ti}$ and $\mathrm{Al}_{3} \mathrm{Ti}$ in the alloyed layer was confirmed. In addition, peaks from the substrate material were also observed. The X-ray diffraction pattern of LSA layer is shown in Fig. 4. Based on the chemical composition analysis (EDS), the alloying elements are evenly distributed in the entire volume of alloyed layer. The average atomic content of titanium in the alloyed layer is $8 \%$ (Fig. 5). In addition, iron-rich secondary phases were revealed throughout the entire melted area (Fig. 6e). Figure 6a shows the image (SE) of precipitates observed in alloyed layer, while Fig. 6b-e the result of elemental mapping analysis of $\mathrm{Ti}, \mathrm{Al}$, $\mathrm{Mg}$ and $\mathrm{Fe}$. The mapping analysis shows that the alloyed layer is dominated by a phase rich in titanium and aluminum, introduced during LSA treatment. Several small precipitates (well below $2 \mu \mathrm{m}$ ) rich in iron have also been revealed on elemental maps. In addition, individual undissolved particles of titanium powder (about $5-35 \mu \mathrm{m}$ in size) were revealed throughout the entire remelting area. Point EDS analysis of Fe-rich precipitates showed an average composition of $88.46 \pm 3.11$ at. $\% \mathrm{Al}, 09.10 \pm 4.9$ at. $\% \mathrm{Fe}$ and $02.44 \pm 1.8$ at. $\% \mathrm{Mg}$. Based on the atomic composition analysis, it can be assumed that this is the $\mathrm{FeAl}_{3}$ phase. Since iron does not form intermetallic phases with magnesium, it was not considered during the analysis. The small amount of magnesium in the EDS analysis comes from the aluminum alloy matrix (AlMg5).

The microhardness measurements were made using an automatic measuring path with a load of $300 \mathrm{gf}$ and indentation time of $15 \mathrm{~s}$. The map of hardness profile along the cross section of the remelted layer is shown in Fig. 7. A significant increase in hardness was found throughout the entire remelting area. The average microhardness of the alloyed layer is about $95 \mathrm{HV}_{03} \pm 8$. As shown in Fig. 7 a, the hardness decreases with the depth of alloyed layer and reaches $69 \mathrm{HV}_{03} \pm 2$ in the area of the parent material. Hardness measurements show an increase in layer hardness of about 19 HRF (Table 3). The increase in hardness in the remelting area is caused by the presence of undissolved Ti powder particles as well as precipitations of $\mathrm{TiAl}_{2}, \mathrm{TiAl}_{3}$ and $\mathrm{FeAl}_{3}$ phases. Slight changes of hardness in the alloyed layer are

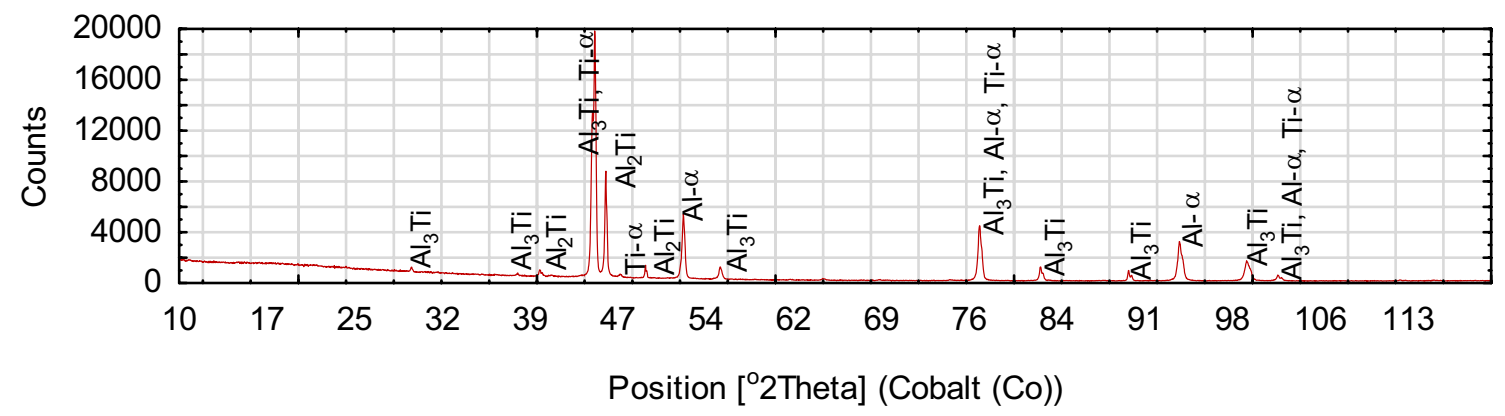

Fig. 4 XRD pattern of AlMg5 aluminum alloy laser surface alloyed with Ti/Fe 
(a)

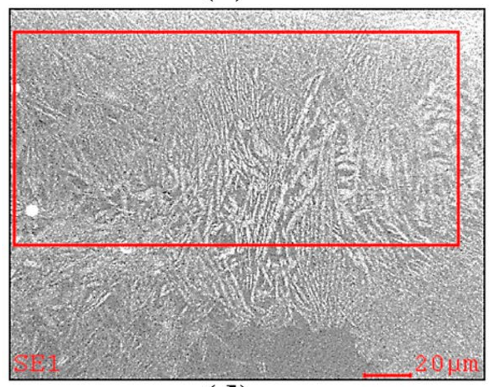

(d)

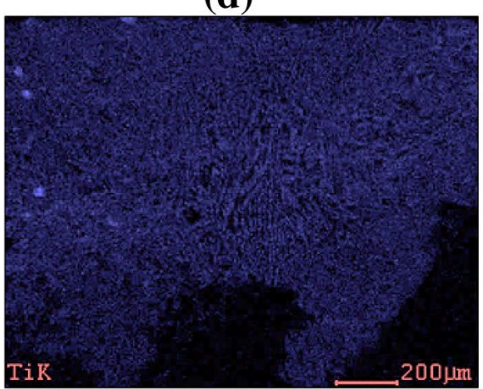

(b)

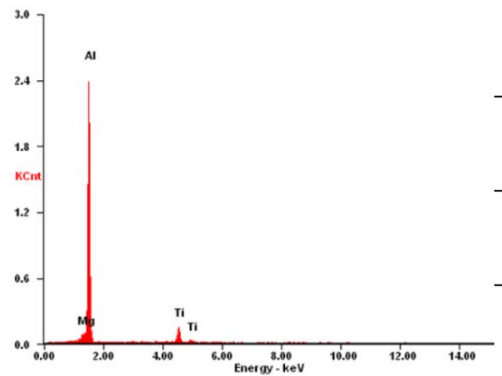

(e)

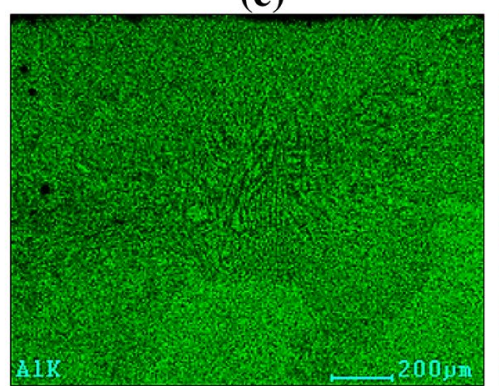

(c)

\begin{tabular}{ccc} 
Element & Wt. \% & At. \% \\
\hline $\mathrm{Mg}$ & 02.70 & 03.17 \\
\hline $\mathrm{Al}$ & 83.63 & 88.66 \\
\hline $\mathrm{Ti}$ & 13.67 & 08.17
\end{tabular}

(f)

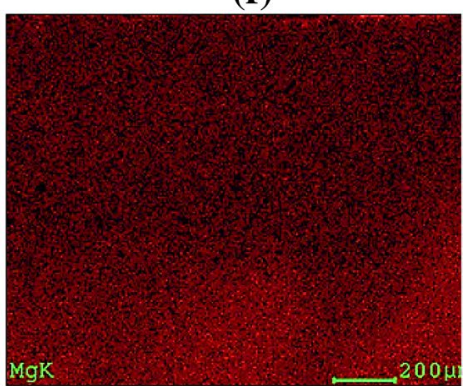

Fig. 5 Microstructure of alloyed layer, $\mathbf{a}$ the remelted zone, $\mathbf{b}$ and $\mathbf{c}$ results of EDS area chemical composition analysis, $\mathbf{d}-\mathbf{f}$ elemental mapping in remelted area

(a)

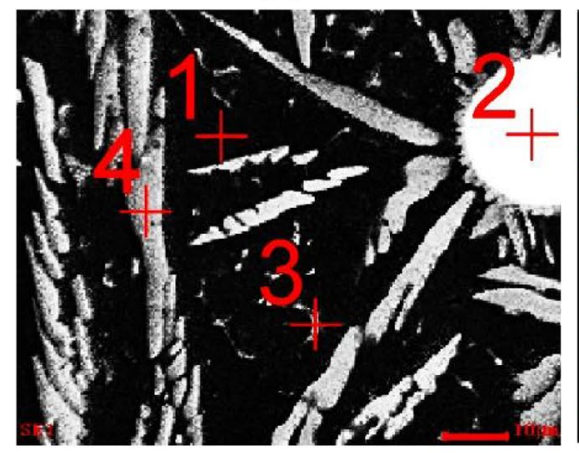

(d)

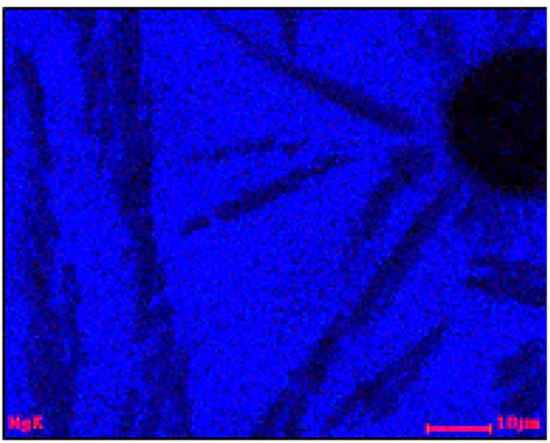

(b)

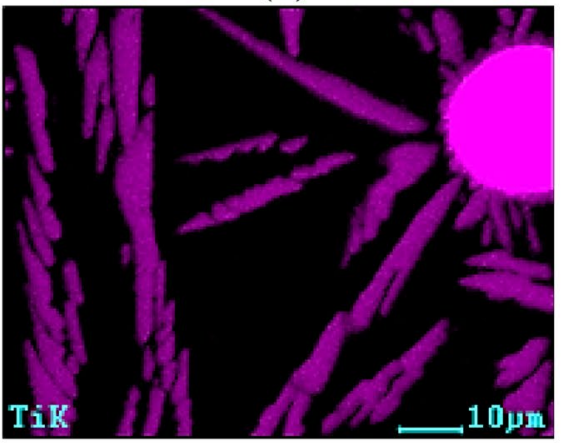

(e)

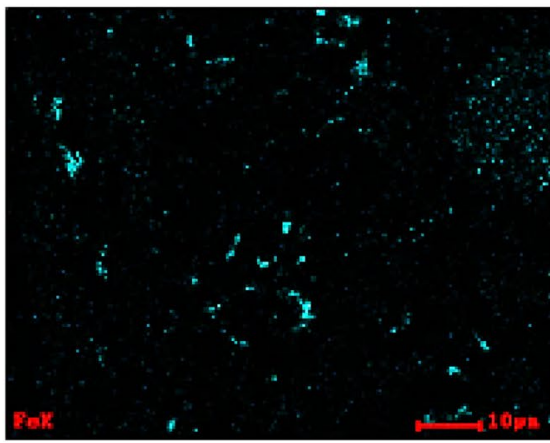

(c)

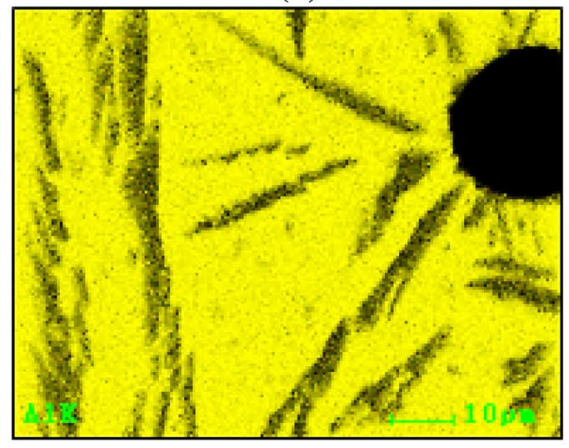

(f)

Atomic concentration of elements from the figure (a)

\begin{tabular}{ccccc}
$\begin{array}{c}\text { Point } \\
\text { no. }\end{array}$ & $\mathrm{Al}$ & $\mathrm{Mg}$ & $\mathrm{Ti}$ & $\mathrm{Fe}$ \\
\hline 1 & 87.45 & 03.74 & 08.80 & 0 \\
\hline 2 & 0 & 0 & 100 & 0 \\
\hline 3 & 88.46 & 02.44 & 0 & $\begin{array}{c}09.1 \\
0\end{array}$ \\
\hline 4 & 76.19 & 0 & 23.81 & 0
\end{tabular}

Fig. 6 Microstructure of LSA layer, a general image (SE), b-e elemental mapping analysis in remelted area, $\mathbf{f}$ results of EDS point analysis from (a) 
(a)

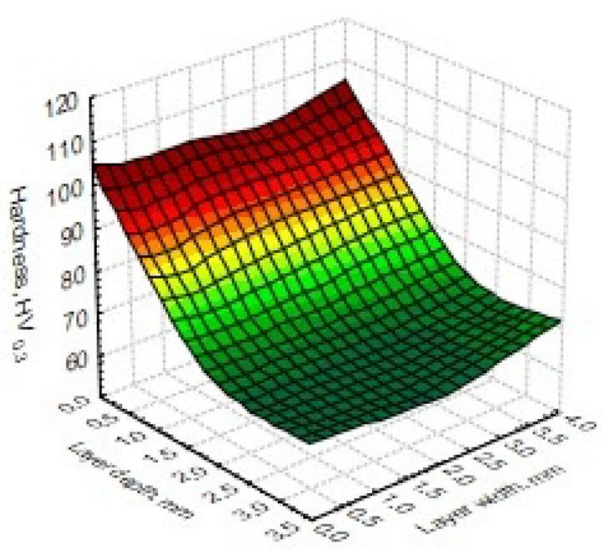

(b)

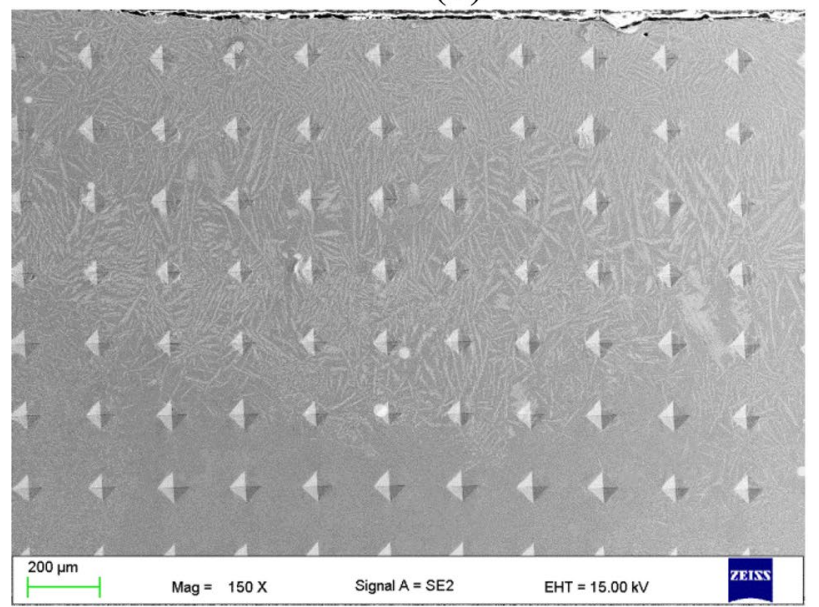

Fig. 7 The hardness distribution in the cross section of alloyed layer and the SE image showing the location of the measuring points the layer

Table 3 Dimensions and roughness of the wear tracks

\begin{tabular}{|c|c|c|c|c|c|c|c|c|}
\hline \multirow[t]{2}{*}{ Tested material } & \multicolumn{3}{|c|}{ Dimensions of plastic deformation } & \multicolumn{3}{|c|}{ Dimensions of wear track } & \multirow{2}{*}{$\begin{array}{l}\text { Roughness of the } \\
\text { wear track } \mathrm{Ra}[\mu \mathrm{m}]\end{array}$} & \multirow[t]{2}{*}{ Hardness } \\
\hline & Height, $\mu \mathrm{m}$ & Width, $\mu \mathrm{m}$ & Volume, $\mathrm{mm}^{3}$ & Depth, $\mu \mathrm{m}$ & Width, mm & Volume, $\mathrm{mm}^{3}$ & & \\
\hline AlMg5 & $13.51 \pm 2.78$ & $93.6 \pm 25.7$ & $0.67 \pm 0.2$ & $43.93 \pm 8.88$ & $1.22 \pm 0.1$ & $27.64 \pm 11.96$ & $1.54 \pm 0.01$ & $63.3 \pm 1.7$ \\
\hline $\mathrm{AlMg} 5+\mathrm{Ti} / \mathrm{Fe}$ & $5.41 \pm 2.03$ & $69.2 \pm 19.4$ & $0.13 \pm 0.1$ & $27.86 \pm 2.77$ & $0.79 \pm 0.04$ & $20.39 \pm 5.28$ & $1.33 \pm 0.03$ & $82.5 \pm 3.9$ \\
\hline
\end{tabular}

caused by variation in the size and share of intermetallic phases (the size of precipitates ranged from 5 to $18 \mu \mathrm{m}$ ), as well as the size of the grains (the grain size in the remelted area was from 4 to $42 \mu \mathrm{m}$ ). The distribution of indentation points in the alloyed area is shown in Fig. 7b.

The analysis of the width and depth of the wear track revealed a significant increase in the wear resistance of samples after laser surface treatment. It reveals a clear correlation between microhardness in cross section and increase in surface hardness, as well as resistance to abrasion.

The wear mechanism was studied based on the wear tracks analysis, as well as observations of debris and comparison of representative areas of wear tracks (Figs. 8, 9). On the surface of wear track after LSA (Fig. 8a, c) and on the surface of the untreated base alloy (Fig. 8b, d) numerous evidences of abrasion wear is revealed in the form of grooves parallel to the direction of movement. This wear effect is mainly due to the presence of aluminum particles in the case of AlMg5 alloy, and in the case of LSA surface of Al-Ti/AlFe phases and undissolved Ti particles that form wear debris between the working surface and the $\mathrm{ZrO}_{2}$ ceramic ball (counter-sample). Abrasion was mainly caused by plowing due to presence of detached fragments of the substrate material between the sample and the counter-sample surface. Moreover, in both cases (untreated surface and LSA surface) delamination areas were revealed. This type of fatigue wear mechanism causes cracking and subsequent tearing of fragments of material in the form of flakes or particles from the surface as a result of repeated ball movement over the sample (Fig. 8a-c). This phenomenon was the most destructive in the aluminum alloy parent material (Fig. 8c). Based on the observations made in the scanning electron microscope and EDS analysis, the aluminum oxides were found in both wear products and on the abrasion surface (Fig. 8e). This is evidence of oxidation wear due to the release of a significant amount of heat during the wear test. A larger amount of oxide was found in case of LSA surface on the sample surface and in the wear debris. Similarly, in both cases, signs of plastic deformation on the wear surface (Fig. 8d) and the presence of the substrate material on the ceramic ball (Fig. 8f, g) were revealed. The average diameter of the material adhered to the surface of the ball was $1.01 \mathrm{~mm}$ for the LSA surface, while for the base material it was $1.35 \mathrm{~mm}$. This phenomenon was much more intense for the base material than for the LSA surface. This kind of material transfer indicates adhesion. The observed plastic deformation of wear paths indicates softening of the material due to the increase in temperature in the contact area.

Microscopic observations revealed a different morphology of debris resulted from wear of the LSA surface and untreated aluminum alloy. In the case of a wear products resulted from tribological test of the base aluminum 
(a)

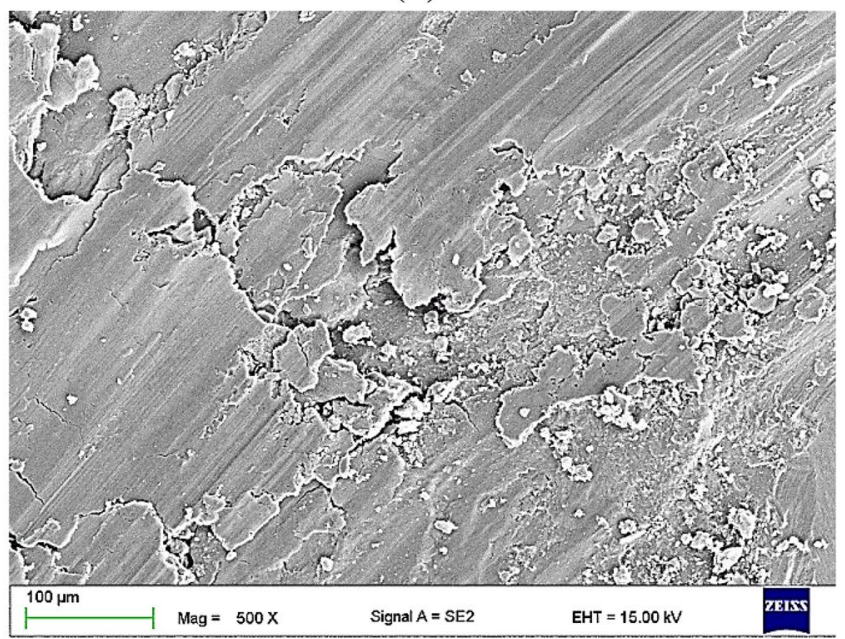

(c)

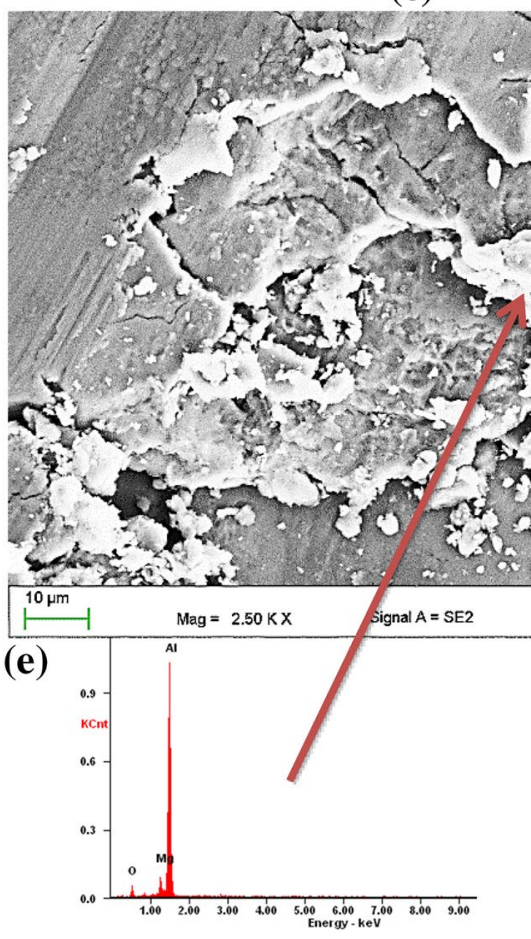

(b)

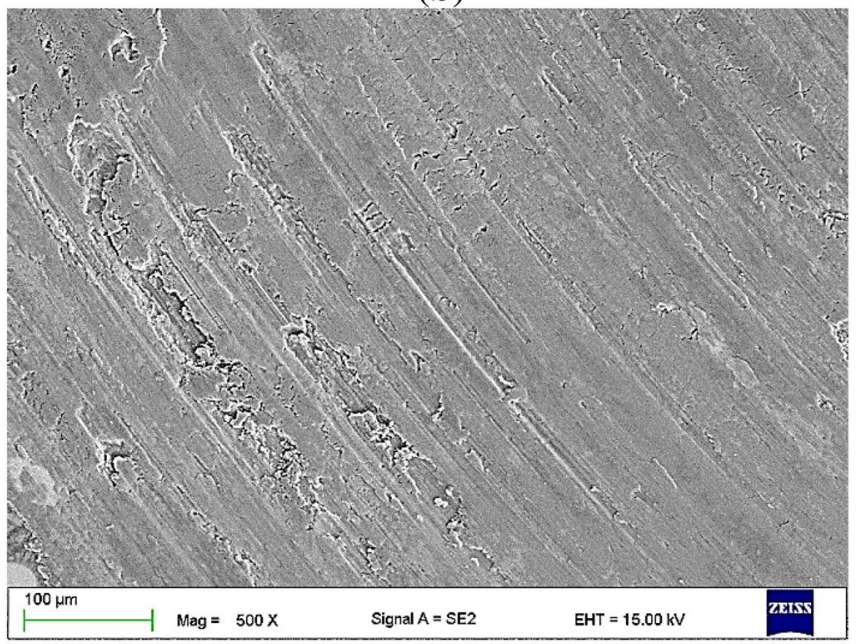

(d)

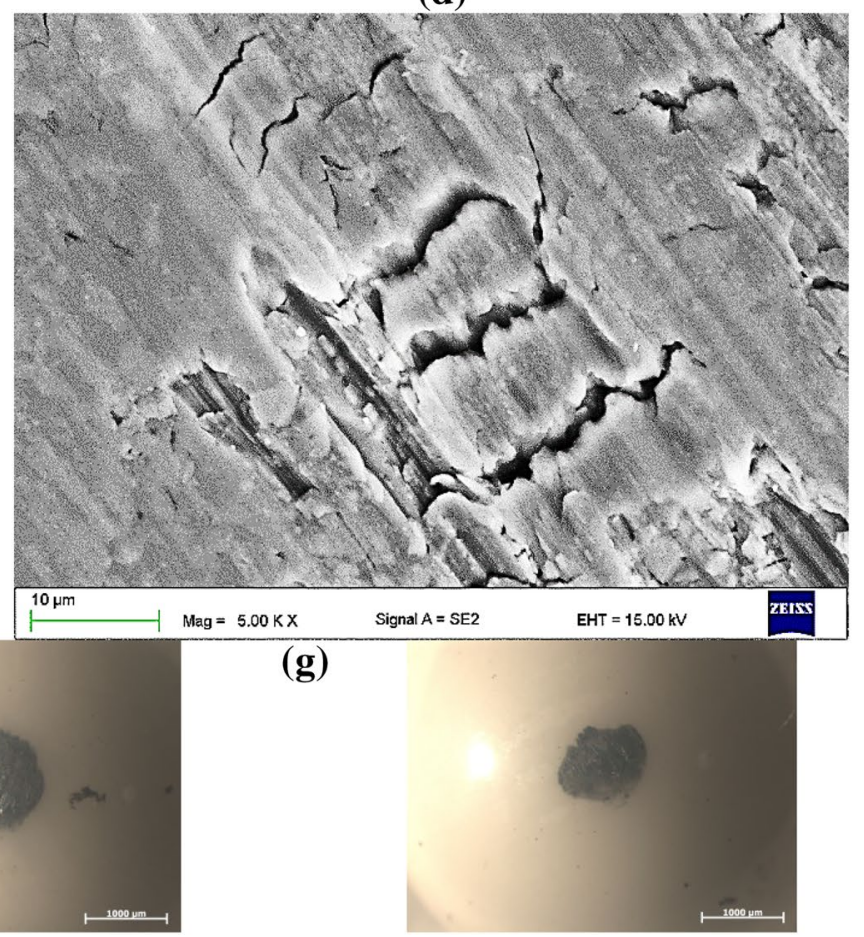

Fig. 8 Wear track surface and counter-samples after tribological test, a, c, f parent material; b, d, $\mathbf{g}$ LSA layer; e EDS analysis from the base material wear track

material, the large flake-shaped fragments with a size of 50-5000 $\mu \mathrm{m}$, detached from base aluminum surface (Fig. 9a) were disclosed. For LSA surface, the wear products consisted of several flakes with a size of $20-100 \mu \mathrm{m}$ and a fine powder below $14 \mu \mathrm{m}$. The wear debris resulting from the tribological test of LSA surface are shown in Fig. 9b.

Wear track on LSA surface was about $16 \mu \mathrm{m}$ shallower and about $430 \mu \mathrm{m}$ narrower compared to the untreated surface of aluminum alloy. In addition, the volume of the LSA wear track was $7.25 \mathrm{~mm}^{3}$ smaller than that of aluminum base alloy. The crater profile is shown in Fig. 10a and the results of wear tracks measurements are summarized in Table 3. The much smaller amount of material located above the surface level and around the wear track (on the wear track profile) in case of LSA surface about $0.54 \mathrm{~mm}^{2}$, indicates a lower plastic deformation due to higher hardness of the LSA zone compared to the parent material-the aluminum alloy. The untreated aluminum material found greater surface roughness and waviness after wear test, which corresponds 
(a)

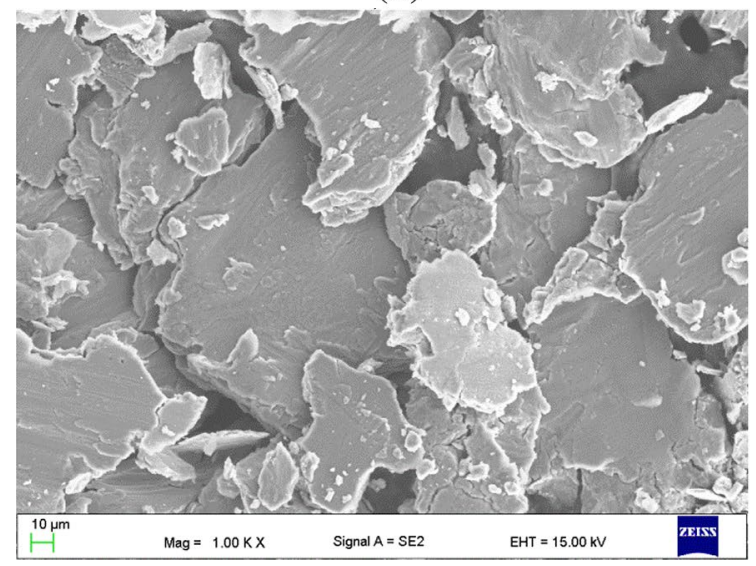

(b)

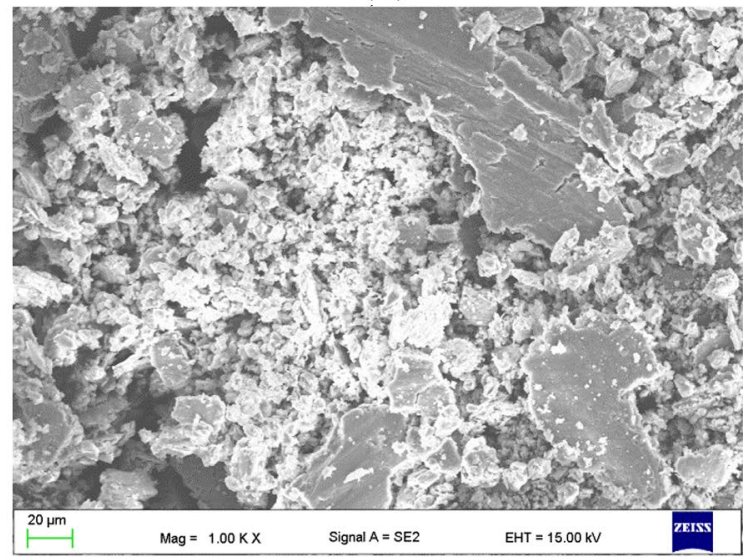

Fig. 9 Wear debris located on the sample surface after the tribological test: a base aluminum material, b LSA layer

(a)

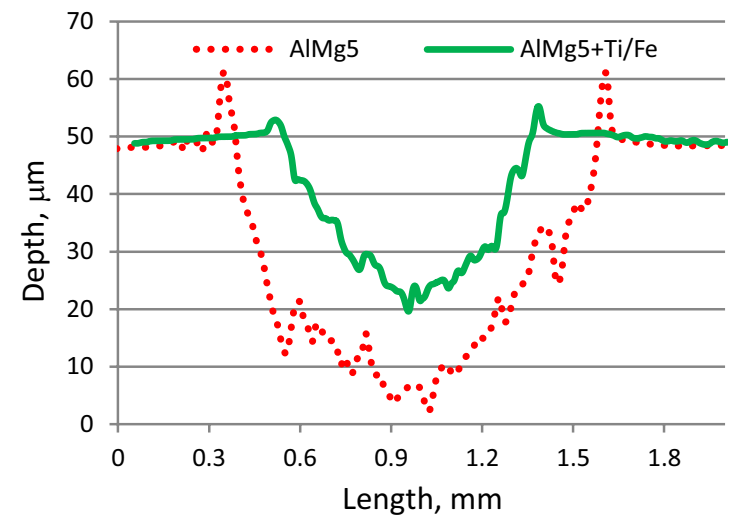

(b)

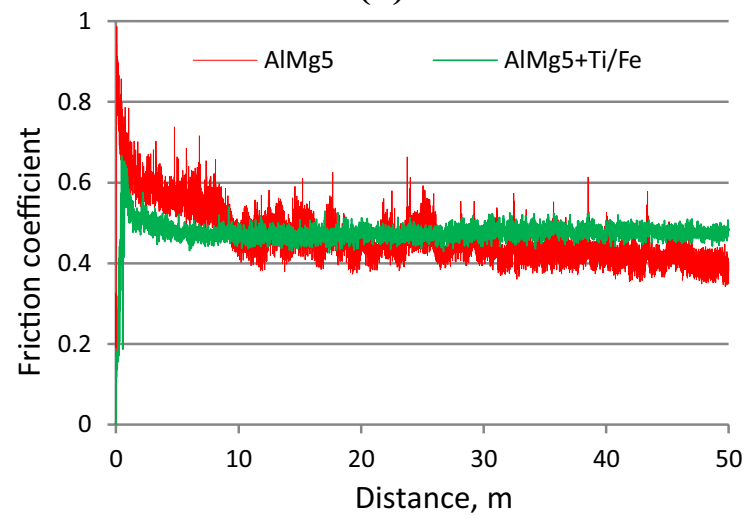

Fig. 10 Wear track (a) and friction coefficient (b) in the tribological test of AlMg5 base material and after LSA with Ti/Fe

to the numerous traces of delamination shown in Fig. 8a, c (Fig. 10; Table 3).

Large fluctuation of friction coefficients indicates the appearance of cracks and intense delamination as well as local melting and softening of the surface during wear test (Fig. 10b). The highest coefficient of friction, in both cases, was revealed when the surface was scratched for about $1 \mathrm{~m}$ after the test started, where the average value for the base aluminum alloy was 0.9 and for LSA surface 0.65 . The average coefficient of friction for untreated surface at the distance of 2-10 $\mathrm{m}$ was much higher than on the LSA surface (where it was ranged from 0.6 to 0.65 ) and from 10 to $25 \mathrm{~m}$ corresponded to 0.45 and after exceeding $25 \mathrm{~m}$ was lower and reached about 0.4 . The friction coefficient measured during the wear test for the LSA surface stabilized after $2 \mathrm{~m}(0.45)$ and its fluctuations were much lower, which confirms the minor influence of delamination on the friction surface.

\section{Conclusion}

As a result of the laser surface treatment of the AlMg5 alloy (power-2 $\mathrm{kW}$; scanning speed of $0.2 \mathrm{~mm} / \mathrm{min}$ ), a homogeneous and wear-resistant tribological layer was obtained without porosity or discontinuities in the structure. The average depth of remelted layer ranged from 
1440 to $2168 \mu \mathrm{m}$. The average grain size of the remelted area is between 4 and $42 \mu \mathrm{m}$. The smallest grain size $(4-15 \mu \mathrm{m})$ was observed in the lower part of remelted layer while in the middle and upper part of remelted zone was from 25 to $42 \mu \mathrm{m}$. The average grain size of AlMg5 alloy without laser surface treatment was in the range from 300 to $590 \mu \mathrm{m}$. In the entire remelted area, only several undissolved alloying powder particles were observed. Based on the chemical composition analysis (EDS) the alloying elements are evenly distributed throughout the entire volume of the alloyed layer. The average atomic content of titanium in the alloyed layer is $8 \%$. The XRD analysis, as well as EDS, revealed the uniform occurrence of $\mathrm{Al}_{2} \mathrm{Ti}$ and $\mathrm{Al}_{3} \mathrm{Ti}$ phases throughout the entire alloyed layer. In addition, EDS analysis confirmed the presence of an iron rich phase, $\mathrm{FeAl}_{3}$. The introduction of $\mathrm{Ti}$ and $\mathrm{Fe}$ in LSA process increased both hardness and tribological resistance of the aluminum AlMg5 surface layer. The average microhardness of LSA layer is about $26 \mathrm{HV}_{03} \pm 2$ higher than the base aluminum material. Hardness measurements show a layer hardness increase of approximately 19 HRF. Wear track on the LSA surface was about $16 \mu \mathrm{m}$ shallower and about $430 \mu \mathrm{m}$ narrower comparing to the untreated surface of aluminum alloy. In addition, the wear track volume of the LSA surface layer was $7.25 \mathrm{~mm}^{3}$ smaller than that of the aluminum base alloy.

Open Access This article is licensed under a Creative Commons Attribution 4.0 International License, which permits use, sharing, adaptation, distribution and reproduction in any medium or format, as long as you give appropriate credit to the original author(s) and the source, provide a link to the Creative Commons licence, and indicate if changes were made. The images or other third party material in this article are included in the article's Creative Commons licence, unless indicated otherwise in a credit line to the material. If material is not included in the article's Creative Commons licence and your intended use is not permitted by statutory regulation or exceeds the permitted use, you will need to obtain permission directly from the copyright holder. To view a copy of this licence, visit http://creativecommons.org/licenses/by/4.0/.

\section{References}

1. W.S. Miller, L. Zhuang, J. Bottema, A.J. Wittebrood, P. De Smet, A. Haszler, A. Vieregge, Recent development in aluminium alloys for the automotive industry. Mater. Sci. Eng. A 280, 37-49 (2000)

2. J.R. Davis, Aluminum and Aluminum Alloys (ASM International, 1993) (ISBN 978-0-87170-496-2)

3. A. Vencl, I. Bobic, S. Arostegui, B. Bobic, A. Marinković, M. Babić, Structural, mechanical and tribological properties of A356 aluminium alloy reinforced with $\mathrm{Al} 2 \mathrm{O} 3, \mathrm{SiC}$ and $\mathrm{SiC}+$ graphite particles. J. Alloys Compd. 506, 631-639 (2010)

4. P. Snopiński, T. Tański, K. Labisz, S. Rusz, P. Jonsta, M. Król, Wrought aluminium-magnesium alloys subjected to SPD processing. IJMR 107, 637-645 (2016)

5. M. Elhefnawey, G.L. Shuai, Z. Li, M. Nemat-Alla, D.T. Zhang, L. $\mathrm{Li}$, On achieving superior strength for Al-Mg-Zn alloy adopting cold ECAP. Vacuum (2020). https://doi.org/10.1016/j.vacuu m.2020.109191

6. T. Tański, K. Labisz, Electron Microscope Investigation of PVD Coated Aluminium Alloy Surface Layer. Solid State Phenom. 186, 192-197 (2012)

7. G. Mrówka-Nowotnik, J. Sieniawski, Influence of heat treatment on the microstructure and mechanical properties of 6005 and 6082 aluminium alloys. J. Mater. Process. Technol. 162-163, 367-372 (2005)

8. R.Z. Valiev, N.A. Krasilnikov, N.K. Tsenev, Plastic deformation of alloys with submicron-grained structure. Mater. Sci. Eng. A. 137, 35-40 (1991)

9. J.A. Picas, A. Forn, R. Rilla, E. Martín, HVOF thermal sprayed coatings on aluminium alloys and aluminium matrix composites. Surf. Coat. Technol. 200, 1178-1181 (2005)

10. G. Bolelli, B. Bonferroni, G. Coletta, L. Lusvarghi, F. Pitacco, Wear and corrosion behaviour of HVOF WC-CoCr/CVD DLC hybrid coating systems deposited onto aluminium substrate. Surf. Coat. Technol. 205, 4211-4220 (2011)

11. T. Tarasova, G. Gvozdeva, R. Ableyeva, Aluminium Matrix Composites Produced by Laser Based Additive Manufacturing. Mater. Today Proc. 11, 305-310 (2019)

12. J. Guo, X. Ma, X. Si, Z. Yang, J. Zhao, Effect of Nanosecond Laser Treatment Parameters on Surface Wettability Behaviour of Pure Aluminium. IOP Conf. Ser. Mater. Sci. Eng. 538, 012021 (2019)

13. T.M. Yue, J.K. Yu, Z. Mei, H.C. Man, Excimer laser surface treatment of Ti-6Al-4V alloy for corrosion resistance enhancement. Mater. Lett. 52, 206-212 (2002)

14. W. Pakieła, T. Tański, Z. Brytan, K. Labisz, The influence of laser alloying on the structure and mechanical properties of AlMg5Si2Mn surface layers. Appl. Phys. A. 122, 352 (2016)

15. A. Hemmasian Ettefagh, H. Wen, A. Chaichi, M.I. Islam, F. Lu, M. Gartia, S. Guo, Laser surface modifications of Fe-14Cr ferritic alloy for improved corrosion performance. Surf. Coat. Technol. 381, 125194 (2020)

16. S. Tomida, K. Nakata, $\mathrm{Fe}-\mathrm{Al}$ composite layers on aluminum alloy formed by laser surface alloying with iron powder. Surf. Coat. Technol. 174-175, 559-563 (2003)

17. R. Galun, A. Weisheit, B.L. Mordike, Laser surface alloying of magnesium base alloys. J. Laser Appl. 8, 299-305 (1996)

18. L.A. Dobrzański, T. Tański, A.D. Dobrzańska-Danikiewicz, E. Jonda, M. Bonek, Drygała A. 1 - Structures, properties and development trends of laser-surface-treated hot-work steels, light metal alloys and polycrystalline silicon, in Laser Surface Engineering; Woodhead Publishing Series in Electronic and Optical Materials, ed. by J. Lawrence, D.G. Waugh, Eds. (Woodhead Publishing, 2015), pp. 3-32. ISBN 978-1-78242-074-3

19. García, I. de la Fuente, J. de Damborenea, J.J. (Ti, Al)/(Ti, Al) $\mathrm{N}$ coatings produced by laser surface alloying. Mater. Lett. 53, 44-51 (2002)

20. J.E. Benci, J.C. Ma, T.P. Feist, Evaluation of the intermetallic compound A12Ti for elevated-temperature applications. Mater. Sci. Eng. A. 192-193, 38-44 (1995)

21. T. Ai, Q. Niu, Z. Deng, X. Yuan, W. Li, Strengthening and toughening of laminated TiAl composite sheets by titanium alloy layers and carbide particles. Int. J. Mater. Res. 110, 740-745 (2019)

22. C.J. Hsu, C.Y. Chang, P.W. Kao, N.J. Ho, C.P. Chang, Al-Al3Ti nanocomposites produced in situ by friction stir processing. Acta Mater. 54, 5241-5249 (2006)

23. X. Sun, J. Tao, X. Guo, Bonding properties of interface in Fe/Al clad tube prepared by explosive welding. Trans. Nonferrous Met. Soc. China 21, 2175-2180 (2011)

24. S. Chen, L. Li, Y. Chen, J. Huang, Joining mechanism of Ti/Al dissimilar alloys during laser welding-brazing process. J. Alloys Compd. 509, 891-898 (2011) 
25. Y. Chen, S. Chen, L. Li, Effects of heat input on microstructure and mechanical property of $\mathrm{Al} / \mathrm{Ti}$ joints by rectangular spot laser welding-brazing method. Int. J. Adv. Manuf. Technol. 44, 265 (2008)

26. J. Dutta Majumdar, B.L. Mordike, I. Manna, Friction and wear behavior of Ti following laser surface alloying with $\mathrm{Si}, \mathrm{Al}$ and $\mathrm{Si}+\mathrm{Al}$. Wear 242(1-2), 18-27 (2000)

27. H. Wang, H. Wang, C. Pan, Vanadium carbide coating growth on die steel substrate in borax salt bath. J. Wuhan Univ. Technol.Mater. Sci. Ed. 25, 600-603 (2010)
28. H.M. Wang, H.B. Tang, L.X. Cai, F. Cao, L.Y. Zhang, R.L. Yu, Microstructure and wear properties of laser clad Ti2Ni3Si/Ni3Ti multiphase intermetallic coatings. Appl. Phys. A 80, 1677-1682 (2005)

Publisher's Note Springer Nature remains neutral with regard to jurisdictional claims in published maps and institutional affiliations. 